Article

\title{
Enhanced Seismic Retrofit of a Reinforced Concrete Building of Architectural Interest
}

\author{
Gloria Terenzi ${ }^{1, *}$, Elena Fuso ${ }^{2}$, Stefano Sorace ${ }^{2}$ and Iacopo Costoli ${ }^{2}$ \\ 1 Department of Civil and Environmental Engineering, University of Florence, 50139 Florence, Italy \\ 2 Polytechnic Department of Engineering and Architecture, University of Udine, 33100 Udine, Italy; \\ fuso.elena@spes.uniud.it (E.F.); stefano.sorace@uniud.it (S.S.); costoli.iacopo@spes.uniud.it (I.C.) \\ * Correspondence: gloria.terenzi@unifi.it; Tel.: +39-55-275-8887
}

Received: 27 September 2020; Accepted: 17 November 2020; Published: 21 November 2020

\begin{abstract}
Modern heritage buildings designed in the 1950s and 1960s often feature poor seismic performance capacities and may require significant retrofit interventions. A representative case study in Florence, i.e., the edifice housing the Automobile Club Headquarters, is examined here. The building was designed in 1959 with an articulated reinforced concrete structure and presents some enterprising solutions for the time, including suspended floors accommodating large glazed curtain wall façades in the main halls. The original design documentation was collected with accurate record research and checked with detailed on-site surveys. Based on the information gained on the structural system by this preliminary investigation, a time-history assessment analysis was carried out. Remarkable strength deficiencies in most members and severe pounding conditions between the two constituting wings, which are separated by a narrow technical gap, were found. As a result, a base isolation retrofit hypothesis is proposed in order to improve the seismic response capacities of the building without altering its elegant architectural appearance, being characterized by large free internal spaces and well-balanced proportions of the main structural members. A substantial performance improvement is obtained thanks to this rehabilitation strategy, as assessed by the achievement of non-pounding response conditions and safe stress states for all members up to the maximum considered normative earthquake level. Furthermore, the very low peak inter-storey drifts evaluated in retrofitted conditions help in preventing damage to the glazed façades and the remaining drift-sensitive non-structural components.
\end{abstract}

Keywords: reinforced concrete structures; modern heritage buildings; seismic assessment; seismic retrofit; base isolation

\section{Introduction}

Italy is a country with an architectural heritage of inestimable value. This also applies to several buildings designed by eminent architects and structural engineers and erected in the 1950s and 1960s, some of which are also included in modern heritage listings. Similar to ordinary buildings belonging to same period [1,2], these 60- through 70-year-old buildings were designed before coordinate national Technical Standards were issued and may require important structural rehabilitation interventions $[3,4]$.

This study is aimed at providing new contributions to this topic, by proposing a base isolation retrofit strategy capable of substantially improving the seismic performance of modern heritage buildings while not causing intrusion to their interiors and preserving their fine architectural appearance.

One of the most interesting architectures of the early 1960s in Florence, i.e., the building housing the Automobile Club Headquarters, as well as a hotel on the upper storeys, is examined as a representative case study. Designed by the renowned Florentine architect Giuseppe Giorgio Gori, it was built between 
1959 and 1961 with a reinforced concrete (R/C) frame structure. Among other distinguishing features, notable figurative structural expressions are represented by R/C "trestles" marking the volume used as offices, aimed at obtaining large free internal spaces, and double cantilevered $\mathrm{R} / \mathrm{C}$ beams in the large hall of the hotel, to which the lateral floors of the hall are suspended, so as to create glazed continuous curtain-wall glazed façades not interrupted by the presence of perimeter columns.

The original design documentation was collected with accurate record research, including site images and related technical development documents. Detailed on-site surveys of the building were also developed to evaluate the correlation of the geometrical dimensions of the exposed elements to the design ones. A seismic assessment analysis carried out on the structure highlights remarkable strength deficiencies in most members, some of which do not pass stress state checks starting from the serviceability design earthquake level. Furthermore, severe pounding conditions are found between the two constituting wings of the building (named Unit 1 and Unit 2 in the following), separated by a narrow technical gap.

In order to substantially improve the seismic performance of the structure without altering its architectural appearance, a base isolation retrofit hypothesis is developed here, as a preliminary study to a possible application on the building to be carried out in the near future. Due to the irregularities in plan and along the height of the building, double concave sliding surface (DCSS) devices are selected for the isolation system, which are similar to the ones adopted in previous retrofit studies carried out by the authors on ordinary R/C buildings [5-8], as well as in the design of new R/C ones [9].

The architectural and structural characteristics of the building, the results of the time-history assessment analyses in current conditions, the design of the isolation system and the seismic performance attained in retrofitted configuration are discussed in the next sections.

\section{Structural Characteristics of the Building}

Two structural plans of the building are shown in Figures 1 and 2. The A-A and B-B vertical sections traced out in the plans are displayed in Figures 3 and 4. In these and in the following drawings, dimensions are expressed in millimeters.

As highlighted by these drawings, the structural system is notably irregular and articulated both in plan and elevation. The technical separation gap between Unit 1 and Unit 2, identified with a dashed blue line in the plans, is equal to $30 \mathrm{~mm}$, i.e., the thickness of the wooden formworks used to cast the columns and the perimeter beams of Unit 2 wing situated in front of Unit 1.

As mentioned in the Introduction, among other peculiarities of the structural system, it can be pointed out that three wide double-end cantilevered beams are found in the hall of Unit 2, with section height variable from $2250 \mathrm{~mm}$, measured at the external faces of the supporting columns, to $1750 \mathrm{~mm}$, at their ends. The beams bear the perimeter columns above, as well as the underlying mezzanine, which is suspended by means of a set of $\phi 22$ steel tie-rods incorporated in $\phi 80$ copper fire-protection casings filled with cementitious mortar (named C10 in the structural plans). The structural details of one of these beams, redrawn from the design documentation, are shown in Figure 5.

The available original design documentation and the development of careful on-site surveys allowed us to reach the "LC3" knowledge level for the structural system, as defined by the Italian Technical Standards [10] and relevant Instructions [11]. Therefore, value 1 was assumed as the "confidence factor", i.e., the additional safety coefficient to be introduced in stress state and displacement-related checks.

The following mechanical properties resulted from the technical design reports, site development and final testing documents: mean cubic compressive strength of concrete equal to $25 \mathrm{MPa}$; yield stress and tensile strength of the reinforcing steel bars equal to 325 and $433 \mathrm{MPa}$, respectively. These values are typical of concrete and steel used at the time in Italy [1,2] for medium-rise R/C frame structures and, especially for concrete, they are remarkably below the strength values currently adopted in the design of R/C structures of similar dimensions in Italy and Europe [12,13]. 


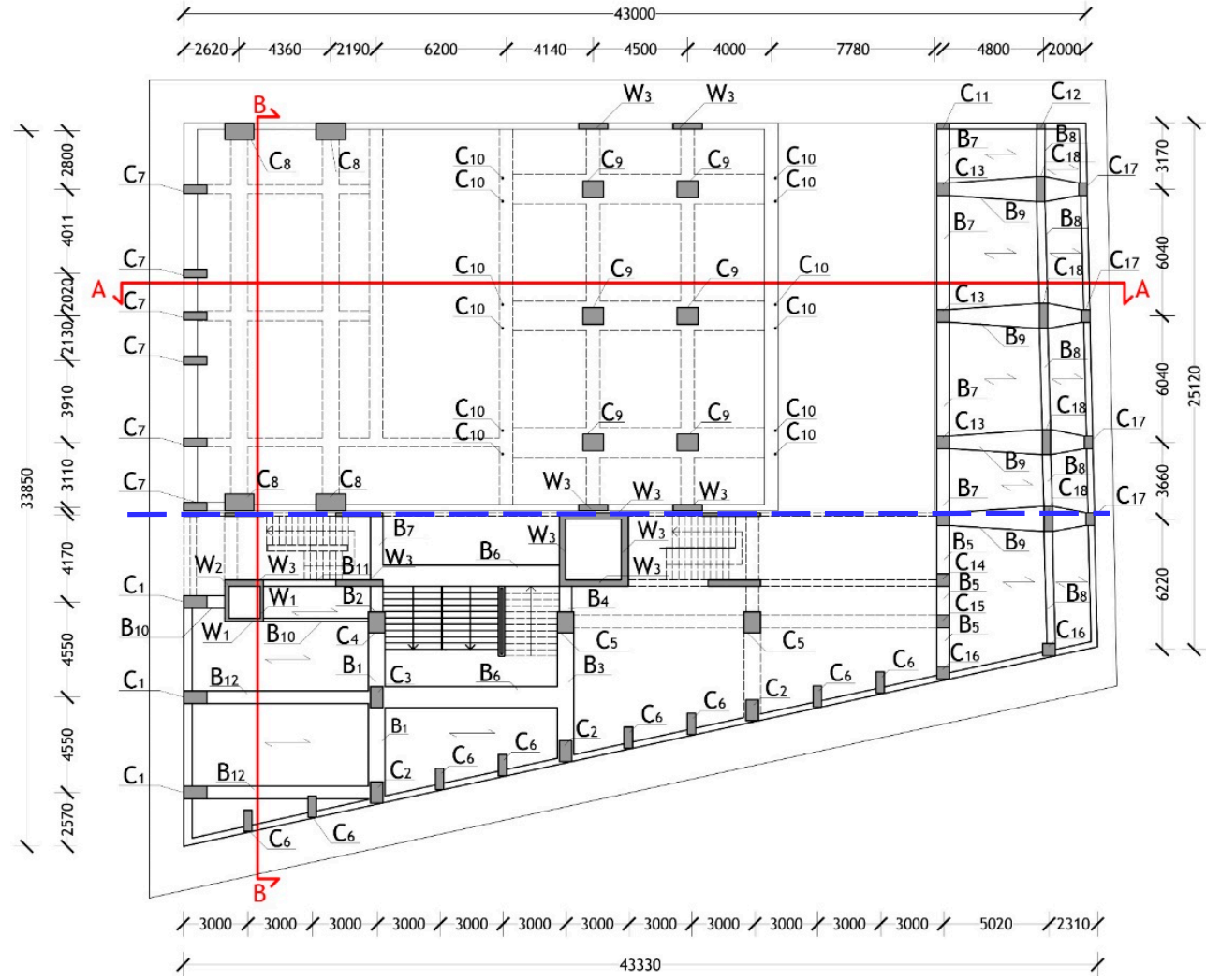

Figure 1. Structural plan of the ground floor.

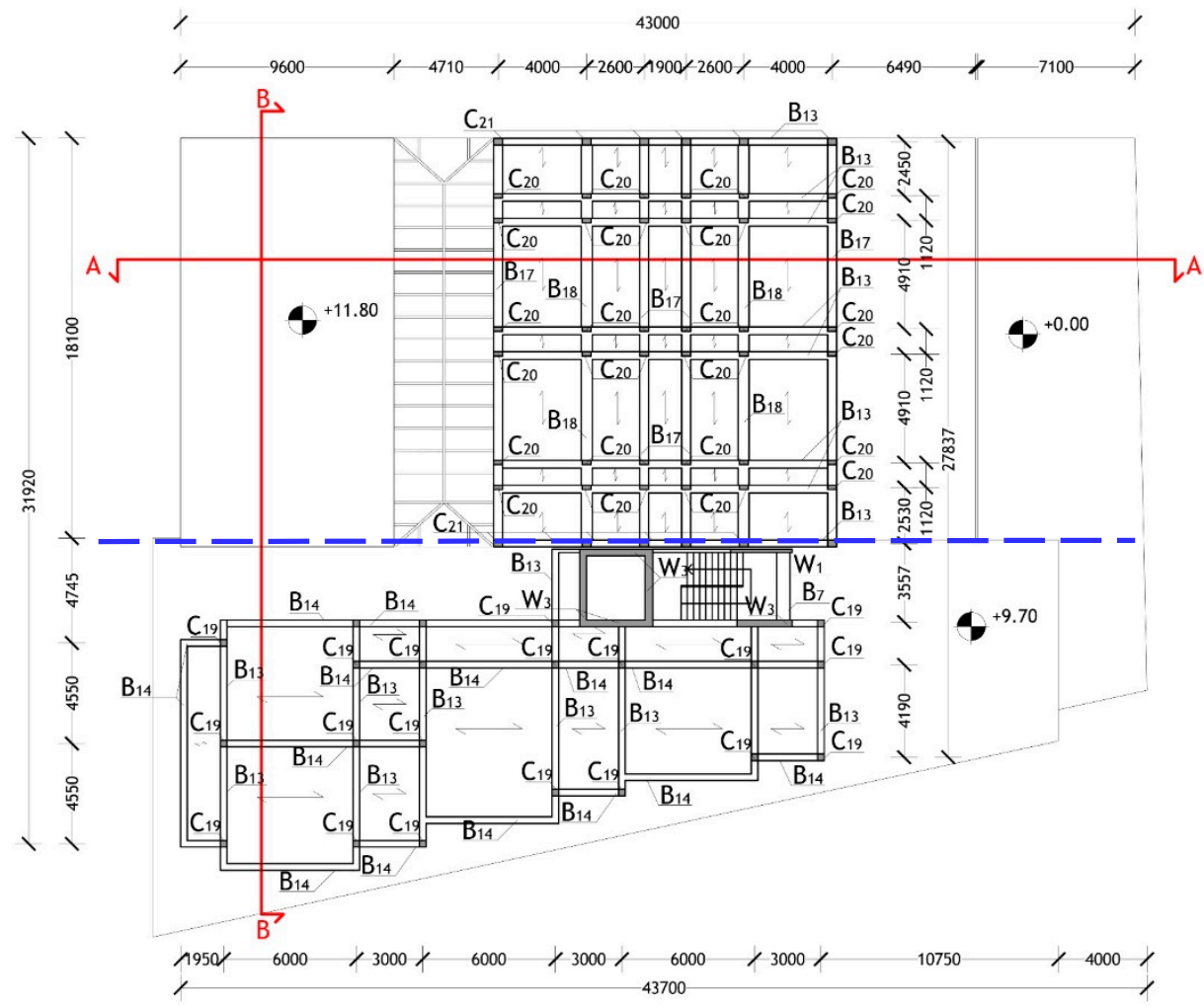

Figure 2. Structural plan of the second through fifth complete floors of the hotel (heights of $14.50 \mathrm{~m}$ through $24.55 \mathrm{~m}$ above ground). 


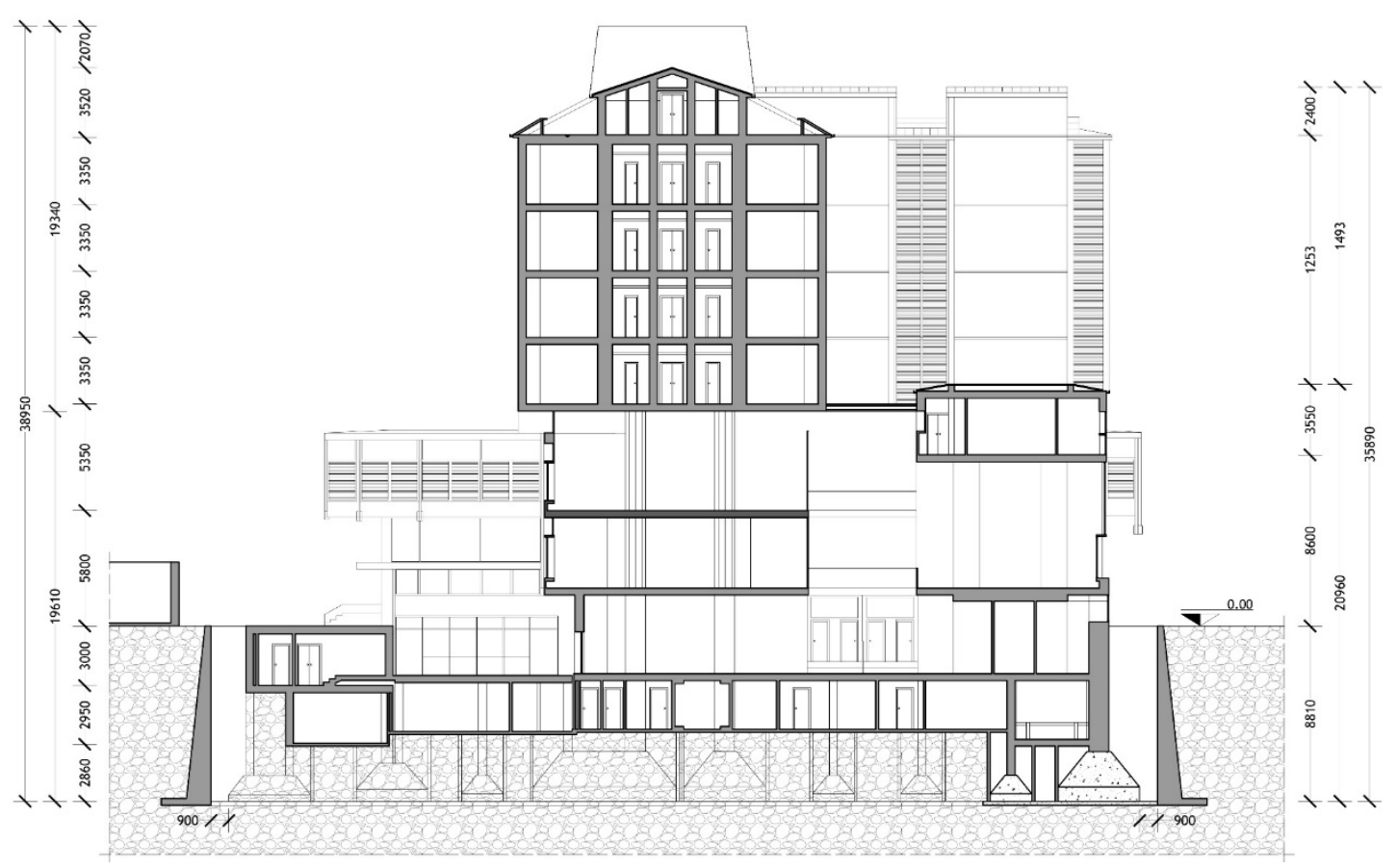

Figure 3. Vertical section of the building denoted as A-A in the structural plans.

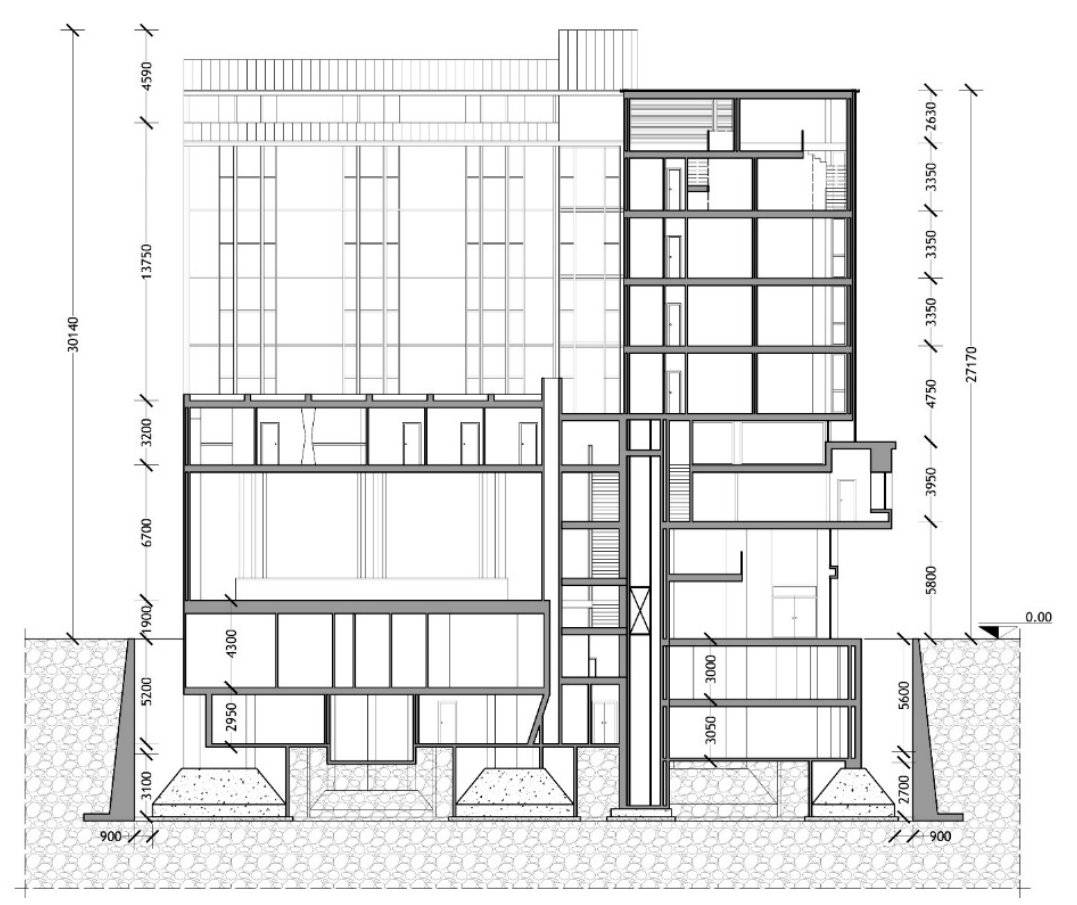

Figure 4. Vertical section of the building denoted as B-B in the structural plans. 


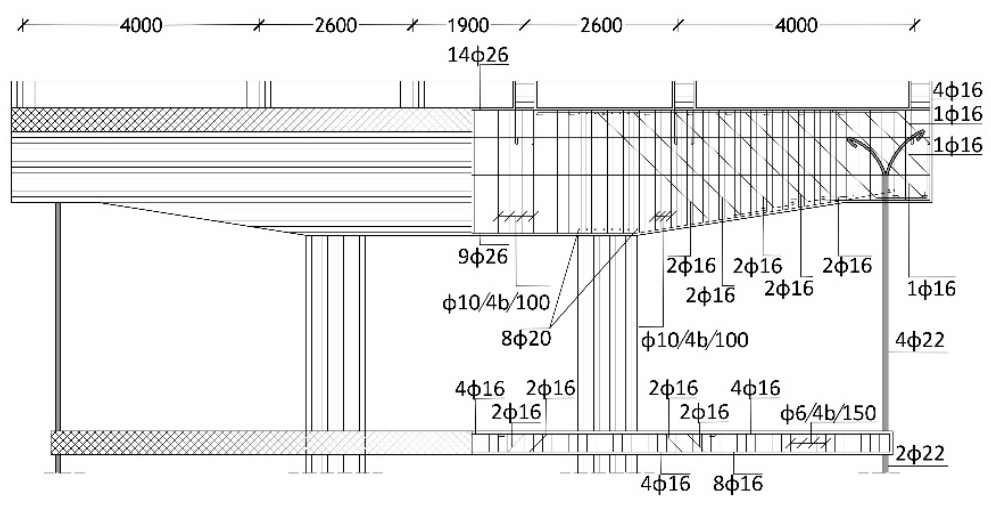

Figure 5. Design drawing of a double-end cantilevered beam situated in the great hall of Unit 2.

Sizes and reinforcing bars of the $\mathrm{R} / \mathrm{C}$ beams, columns and walls are recapitulated in Tables $1-3$, where they are listed according to the numbering in Figures 1 and 2.

Table 1. Size and reinforcement of beams.

\begin{tabular}{ccccccc}
\hline \multirow{2}{*}{ Beams } & Size & \multicolumn{2}{c}{ Half-Span Section } & \multicolumn{2}{c}{ End Sections } & Stirrups \\
\cline { 3 - 7 } & $(\mathbf{m m} \times \mathbf{m m})$ & Top Bars & Bottom Bars & Top Bars & Bottom Bars & $\boldsymbol{\phi} /$ Spacing \\
\hline B1 & $800 \times 350$ & $2 \phi 16+4 \phi 20$ & $2 \phi 16+\phi 20$ & $2 \phi 16+6 \phi 20$ & $2 \phi 16+6 \phi 20$ & $\phi 10 / 150$ \\
B2 & $600 \times 350$ & $2 \phi 16$ & $2 \phi 16$ & $2 \phi 16$ & $2 \phi 16$ & $\phi 10 / 150$ \\
B3 & $800 \times 350$ & $4 \phi 12$ & $4 \phi 12+3 \phi 16$ & $4 \phi 12+5 \phi 16$ & $4 \phi 12$ & $\phi 10 / 150$ \\
B4 & $600 \times 350$ & $2 \phi 12$ & $2 \phi 12$ & $2 \phi 12$ & $2 \phi 12$ & $\phi 10 / 150$ \\
B5 & $800 \times 350$ & $2 \phi 12$ & $4 \phi 12$ & $4 \phi 12$ & $2 \phi 12$ & $\phi 8 / 150$ \\
B6 & $1000 \times 350$ & $18 \phi 22$ & $18 \phi 22$ & $18 \phi 22$ & $18 \phi 22$ & $\phi 8 / 150$ \\
B7 & $600 \times 350$ & $2 \phi 12$ & $4 \phi 12$ & $4 \phi 12$ & $2 \phi 12$ & $\phi 8 / 150$ \\
B8 & $400 \times 350$ & $2 \phi 12$ & $4 \phi 12$ & $4 \phi 12$ & $2 \phi 12$ & $\phi 8 / 150$ \\
B9 & $600 \times 300$ & $4 \phi 12$ & $2 \phi 12$ & $4 \phi 12$ & $2 \phi 12$ & $\phi 8 / 150$ \\
B10 & $350 \times 150$ & $2 \phi 12$ & $2 \phi 12$ & $2 \phi 12$ & $2 \phi 12$ & $\phi 8 / 150$ \\
B11 & $300 \times 350$ & $2 \phi 12$ & $4 \phi 12$ & $4 \phi 12$ & $2 \phi 12$ & $\phi 8 / 150$ \\
B12 & $600 \times 350$ & $2 \phi 16$ & $2 \phi 16+2 \phi 12$ & $2 \phi 16+4 \phi 12$ & $2 \phi 16$ & $\phi 8 / 150$ \\
B13 & $300 \times 350$ & $2 \phi 16$ & $2 \phi 16+2 \phi 20$ & $2 \phi 16+2 \phi 20$ & $2 \phi 16$ & $\phi 8 / 150$ \\
B14 & $300 \times 350$ & $2 \phi 16$ & $3 \phi 16$ & $3 \phi 16$ & $2 \phi 16$ & $\phi 10 / 150$ \\
B17 & $400 \times 350$ & $2 \phi 16$ & $2 \phi 16$ & $2 \phi 16$ & $2 \phi 16$ & $\phi 10 / 150$ \\
B18 & $500 \times 650$ & $4 \phi 16$ & $4 \phi 16$ & $4 \phi 16$ & $4 \phi 16$ & $\phi 10 / 150$ \\
\hline
\end{tabular}


Table 2. Size and reinforcement of columns.

\begin{tabular}{lccc}
\hline Columns & $\begin{array}{c}\text { Size } \\
(\mathbf{m m} \times \mathbf{m m})\end{array}$ & Reinforcing Bars & Stirrups \\
\hline C1 & $1100 \times 600$ & $8 \phi 26$ & $\phi 10 / 250$ \\
C2 & $1000 \times 600$ & $8 \phi 26$ & $\phi 10 / 250$ \\
C3 & $1000 \times 600$ & $8 \phi 26$ & $\phi 10 / 250$ \\
C4 & $1000 \times 800$ & $8 \phi 26$ & $\phi 10 / 250$ \\
C5 & $1000 \times 800$ & $8 \phi 26$ & $\phi 10 / 250$ \\
C6 & $1000 \times 400$ & $6 \phi 26$ & $\phi 10 / 250$ \\
C7 & $1000 \times 400$ & $6 \phi 26$ & $\phi 10 / 250$ \\
C8 & $1400 \times 800$ & $8 \phi 30+8 \phi 20$ & $\phi 8 / 200$ \\
C9 & $1000 \times 800$ & $8 \phi 30+10 \phi 20+4 \phi 16$ & $\phi 8 / 200$ \\
C10 & Steel Cable & $\phi 22$ & - \\
C11 & $600 \times 300$ & $4 \phi 20$ & $\phi 10 / 200$ \\
C12 & $400 \times 300$ & $4 \phi 20$ & $\phi 10 / 200$ \\
C13 & $600 \times 600$ & $8 \phi 20$ & $\phi 10 / 200$ \\
C14 & $600 \times 600$ & $8 \phi 20$ & $\phi 10 / 200$ \\
C15 & $600 \times 600$ & $6 \phi 26$ & $\phi 10 / 250$ \\
C16 & $600 \times 600$ & $4 \phi 20$ & $\phi 10 / 200$ \\
C17 & $600 \times 400$ & $4 \phi 20$ & $\phi 10 / 200$ \\
C18 & $1200 \times 400$ & $8 \phi 26$ & $\phi 10 / 200$ \\
C19 & $300 \times 300$ & $4 \phi 20$ & $\phi 10 / 150$ \\
C20 & $400 \times 200$ & $4 \phi 16$ & $\phi 10 / 150$ \\
C21 & $400 \times 300$ & $4 \phi 16$ & $\phi 10 / 150$ \\
\hline
\end{tabular}

Table 3. Size and reinforcement of walls.

\begin{tabular}{cccc}
\hline Walls & $\begin{array}{c}\text { Size } \\
(\mathbf{m m} \times \mathbf{m m})\end{array}$ & $\begin{array}{c}\text { Reinforcing } \\
\text { Bars }\end{array}$ & Stirrups \\
\hline W1 & $1850 \times 150$ & $14 \phi 8$ & $\phi 12 / 20$ \\
W2 & $1850 \times 300$ & $14 \phi 8$ & $\phi 12 / 20$ \\
W3 & $1400 \times 300$ & $12 \phi 8$ & $\phi 12 / 20$ \\
W3 & $1850 \times 300$ & $14 \phi 8$ & $\phi 12 / 20$ \\
W3 & $1850 \times 300$ & $20 \phi 8$ & $\phi 12 / 20$ \\
W3 & $2250 \times 300$ & $24 \phi 8$ & $\phi 12 / 20$ \\
W1 & $1850 \times 150$ & $14 \phi 8$ & $\phi 12 / 20$ \\
\hline
\end{tabular}

\section{Seismic Assessment Analysis in Current Condition}

The structural analyses were carried out by the finite element model displayed in Figure 6, generated by the SAP2000NL calculus program [14]. Elastic frame elements were used for the R/C beams and columns, shells for the $\mathrm{R} / \mathrm{C}$ walls and cables for the hanging steel tie-rods connected to the cantilevered beams.

Pounding between Unit 1 and Unit 2 was simulated by the non-linear model conceived and implemented in $[15,16]$, which is based on Jankowski's rheological scheme [17] sketched in Figure 7 for two colliding rigid masses, $m_{1}$ and $m_{2}$, with a separation gap at rest width equal to gap ${ }_{r}$.

As shown in Figure 7, Jankowski's model consists of a non-linear spring with $k_{H}$ stiffness, capable of transmitting impact forces, and a non-linear viscous damper with damping coefficient $c_{n l}$, reproducing the energy dissipation caused by impact. A second gap element, $g a p_{c}$, is placed in series with the damper, so as to activate it at the approaching stage of the colliding structures. An elastic spring with stiffness $k_{d}$ is placed in parallel with the damper, to drive it to its pre-impact position before a new contact occurs. 


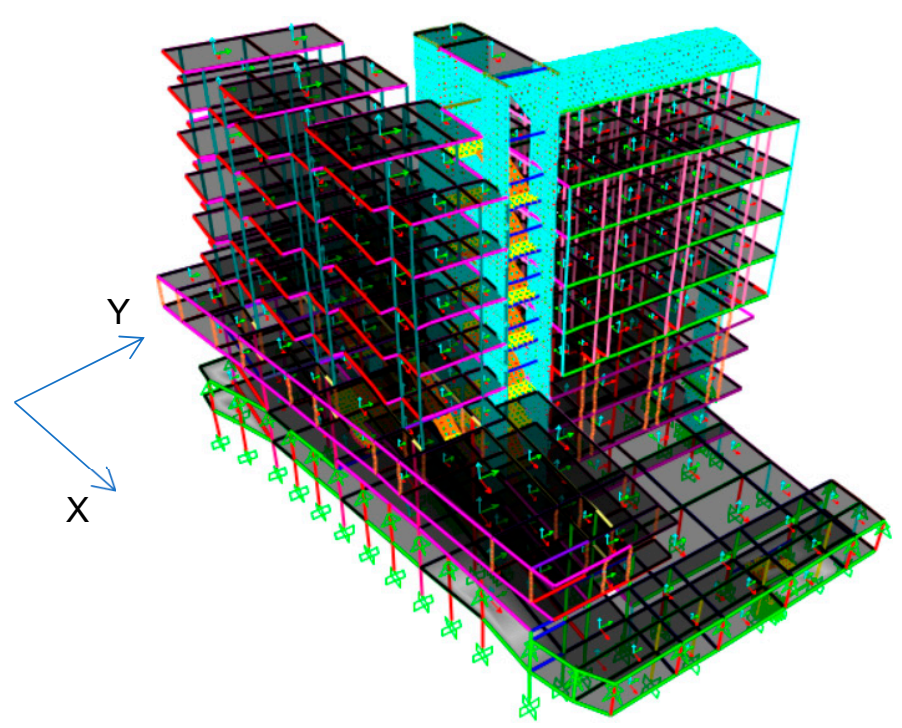

Figure 6. Overall view of the finite element model of the structure.

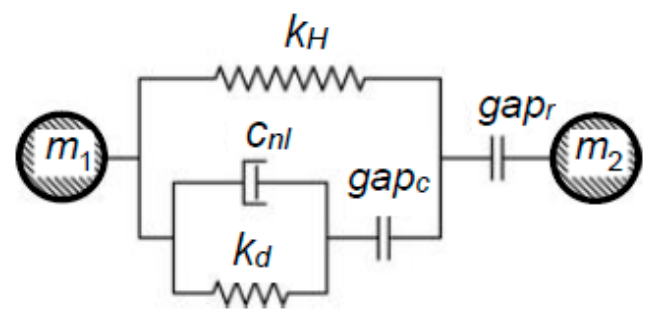

Figure 7. Rheological scheme of Jankowski's non-linear viscoelastic impact model.

The effective impact stiffness $k_{H}$ of the force-transmitting spring is given by [17]

$$
k_{H}(t)=\beta \cdot \sqrt{u_{1}(t)-u_{2}(t)-g a p_{r}}
$$

where $u_{1}(t), u_{2}(t)$ are the displacements of the first and second mass, respectively, both functions of time, $t$, and $\beta$ is the stiffness parameter providing the spring contact force, $F_{s}$, by the following Hertz-type relation [17]:

$$
F_{S}(t)=\beta \cdot\left(u_{1}(t)-u_{2}(t)-g a p_{r}\right)^{\frac{3}{2}}
$$

For impacting R/C frame structures, like Units 1 and $2, \beta$ is normally set as equal to $2.75 \times 10^{6} \mathrm{kN} / \mathrm{m}^{3 / 2}[18,19]$. The damping coefficient of the non-linear damper, $c_{n l}$, is defined as [17]

$$
c_{n l}(t)=2 \xi \sqrt{\frac{m_{1} m_{2}}{m_{1}+m_{2}} \beta \cdot \sqrt{u_{1}(t)-u_{2}(t)-g a p_{r}}}
$$

where $\xi$ is the impact damping ratio [17]:

$$
\xi=\frac{9 \sqrt{5}}{2} \frac{\left(1-e^{2}\right)}{e[e(9 \pi-16)+16]}
$$

with $e=$ coefficient of restitution, basically fixed at 0.65 in concrete-to-concrete impact problems $[19,20]$. Assuming this $e$ value, $\xi=0.373$ results.

The finite element model used in this study to take into account pounding effects in the seismic assessment analyses, proposed in $[15,16]$ to simulate the time-dependent damping coefficient 
expression (3), is constituted by an in-series assemblage of five linear dashpots and five associated in-parallel linear springs. The sequential activation (approaching stage) and disconnection (restitution stage) of dampers allows us to reproduce the evolution of $c_{n l}$. Dampers are denoted by relevant damping coefficients $c_{i}$ (with $i=1, \ldots, 5$ ) in the multi-linear viscoelastic model scheme drawn in Figure 8.

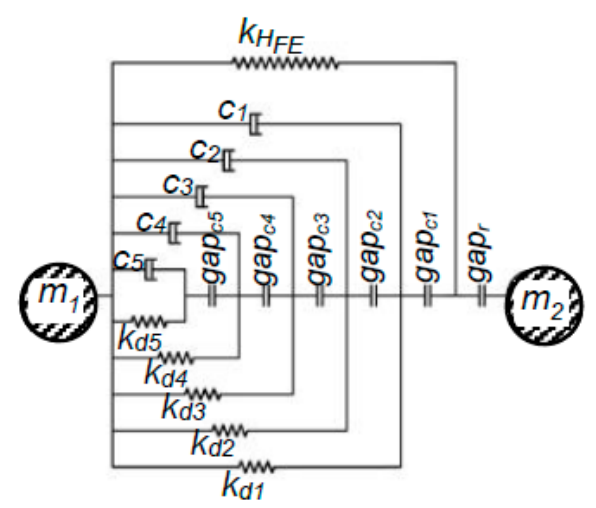

Figure 8. Multi-linear viscoelastic finite element model.

A gap element, denoted as $g a p_{c i}$ in Figure 8, is placed in series with each damper, which is activated when the connected gap closes and driven to its initial position by a linear spring incorporated in parallel, with stiffness $k_{d i}$. A non-linear Hertzian spring, with stiffness $k_{H F E}$, and the separation gap at rest gap $_{r}$, simulating the corresponding components in Jankowski's scheme, complete the finite element contact model.

For the development of time-history analyses, the multi-linear viscoelastic model was positioned across the 30-mm-wide separation gap by linking four joints belonging to Unit 1 to four facing joints of Unit 2, located on the upper floor of the two buildings, at a $H_{c}$ height of $24.55 \mathrm{~m}$ above ground. The positions of the four assemblages are visualized in the general and zoomed finite element model views displayed in Figure 9. The overlying pitched roof of Unit 2 is separated by a wider gap from the elevator-stair block of Unit 1; therefore, pounding effects between these building portions are impaired.

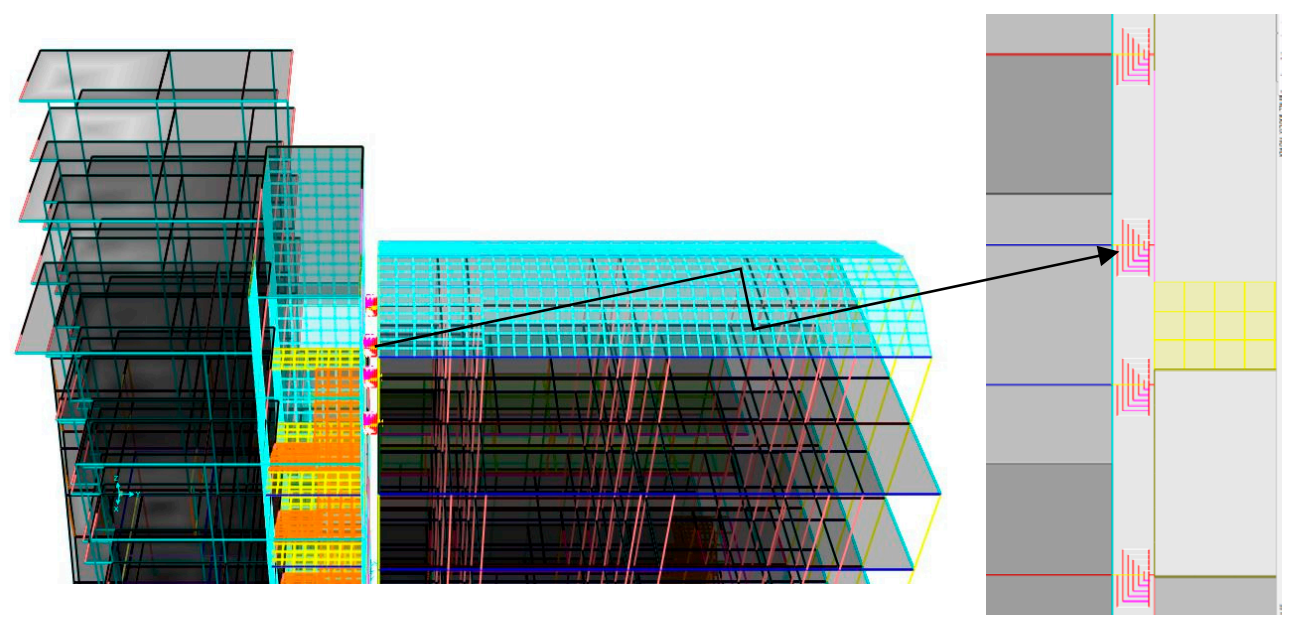

Figure 9. Model view showing the separation gap at rest and zoomed view of the four multi-linear viscoelastic assemblages incorporated between pairs of facing joints of Units 1 and 2.

The computational parameters of the contact elements were calibrated according with the criteria formulated in [15]. More specifically, based on the above-mentioned $H_{c}=24.55 \mathrm{~m}$ height of the linked joints of the two units, the tentative value of the maximum interpenetration 
depth expected from the time-history analysis, $\delta_{\max , t}$-by which the calibration of the finite element contact model is initialized-was fixed at $12.3 \mathrm{~mm}$, i.e., the maximum value of the range $\left(2.5 \times 10^{-4} \times H_{c}=6.15 \mathrm{~mm}-5 \times 10^{-4} \times H_{c}=12.3 \mathrm{~mm}\right)$ located with the above-mentioned criteria [15]. The selection of the upper value is motivated by the dimensions and masses of the two units, which qualify them as medium- to high-rise structures (the minimum value of the range is suggested in [15] for low-rise structures, and the mean value for medium-rise ones). Based on the tentative $\delta_{\max , t}$ estimate, all remaining parameters of the contact elements were derived accordingly.

\subsection{Modal Analysis}

The modal analysis of the structure highlights a main translational mode along $\mathrm{X}$ of Unit 1 , with a vibration period of $0.795 \mathrm{~s}$, and Unit 2, with a period of $1.072 \mathrm{~s}$; and a main translation mode along $Y$ of Unit 1, with a period of $0.989 \mathrm{~s}$, and Unit 2, with a period of $1.361 \mathrm{~s}$. Due to the wide geometrical dimensions and the complexity of the mesh, 30 modes are needed to activate more than $90 \%$ of the total seismic mass of the model along $X$ and $Y$, and a total of 52 modes around $Z$.

\subsection{Time-History and Seismic Performance Assessment Analysis}

The performance assessment analysis was carried out for the four reference seismic levels established in the Italian Technical Standards, i.e., Frequent Design Earthquake (FDE, with $81 \%$ probability of being exceeded over the reference time period $\left.V_{R}\right)$, Serviceability Design Earthquake (SDE, with $63 \% / V_{R}$ probability), Basic Design Earthquake (BDE, with $10 \% / V_{R}$ probability) and Maximum Considered Earthquake (MCE, with $5 \% / V_{R}$ probability). The $V_{R}$ period is fixed at 75 years, which is obtained by multiplying the nominal structural life $V_{N}$ of 50 years by a coefficient of use $C_{u}$ equal to 1.5 , imposed to buildings with significant crowding conditions, like the case study. The reference site parameters are as follows: topographic category T1 (flat surface), and B-type (medium-hard) soil. Relevant pseudo-acceleration elastic response spectra at linear viscous damping ratio of $5 \%$ are plotted in Figure 10.

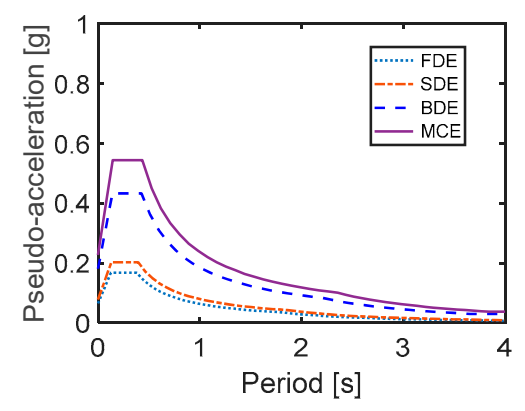

(a)

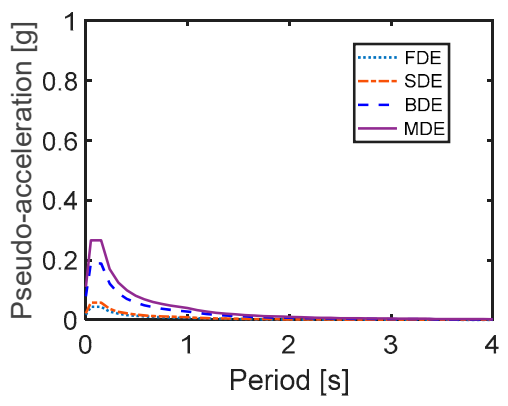

(b)

Figure 10. Normative pseudo-acceleration elastic response spectra for Florence and the reference site parameters-horizontal (a) and vertical (b) components.

For the development of time-history analyses, artificial ground motions were generated in families of seven by SIMQKE-II software [21] from the spectra above, both for the horizontal components (two families) and the vertical component (one family). In each analysis, the accelerograms were applied in groups of two simultaneous horizontal components, with the first one selected from the first generated family of seven motions and the second one selected from the second family, plus the vertical component.

The results of the analysis are synthesized in terms of pounding response, maximum stress states in the structural elements and maximum relative displacement of the upper storeys of the two units at the MCE. 
The relative displacement and mutual collision force time-histories obtained for a pair of contacting joints are illustrated in Figure 11. The relative displacements repeatedly exceed the separation gap width of $30 \mathrm{~mm}$, highlighted by a dashed segment in the graph, reaching a maximum interpenetration depth of $14.1 \mathrm{~mm}$, i.e., acceptably close to the tentatively predicted value of $12.3 \mathrm{~mm}$ fixed by the calibration process of the multi-linear viscoelastic model.

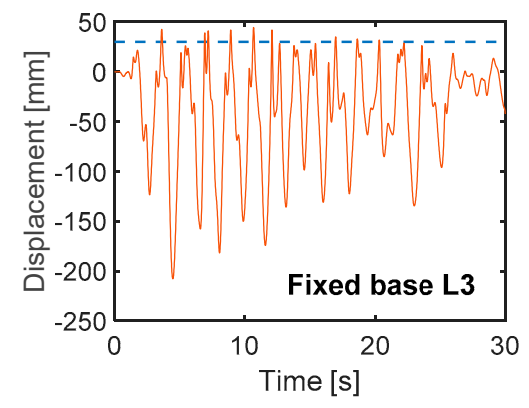

(a)

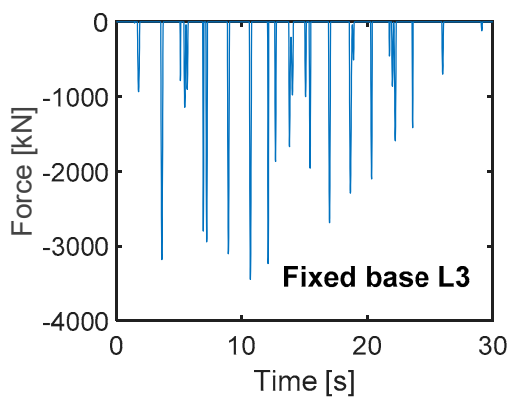

(b)

Figure 11. Relative displacement (a) and contact force (b) time-histories of a pair of contacting joints obtained from the most demanding MCE-scaled group of input accelerograms.

The corresponding collision forces reach peak values of around $3300 \mathrm{kN}$. As the response of the other three contacting joint pairs is very similar, the resulting total collision forces are greater than $13,000 \mathrm{kN}$, which would cause severe damage to the infills in contact with the columns of the colliding alignments, in addition to a significant increase in the stress states of the latter and complete disruption of the concrete cover of the beams belonging to the same alignments. At the same time, the considerable amount of energy dissipated by the local damage effects on the upper storey prevents pounding between the underlying storeys of the two units, for which the maximum relative displacements reach $29 \mathrm{~mm}$.

The stress states computed from the analyses were checked by comparing the maximum values obtained for each structural member with relevant safe domain. As a result, the checks showed general unsafe response conditions of columns and beams. By way of example of the response of columns, the $M_{l c, 1}-M_{l c, 2}$ biaxial moment interaction curves- $-M_{l c, 1}, M_{l, 2}$ being the bending moments around the local axes 1 and 2 of columns in plan, with 1 parallel to $X$, and 2 to $Y$-graphed by jointly plotting the two bending moment response histories, are presented in Figure 12 for a C21-type column of Unit 2 facing the separation gap at the upper storey (the top section of which is connected to one of the four multi-linear viscoelastic models), and a C20-type column belonging to the first storey of the same unit. As shown in Table 2, the two columns have sides of $400 \mathrm{~mm}$ along $X$ and $300 \mathrm{~mm}$ along $Y$ (C21), and $400 \mathrm{~mm}$ along $X$ and $200 \mathrm{~mm}$ along Y (C20). Both columns are reinforced by four Ø16 vertical bars and $\varnothing 10$ stirrups spaced at $150 \mathrm{~mm}$. The bending moment interaction domains of the two columns, traced out for the value of the axial force referred to the basic combination of gravity loads, are also shown in the two graphs.

The response curves highlight maximum $M_{l c, 1}-M_{l c, 2}$ combined values of around 5.9 (C21) and 3.1 (C20) times greater than the corresponding values situated on the safe domain boundaries. Remarkably unsafe response conditions are checked from the response at the BDE too, with severe pounding conditions determining peak interpenetration depth values of $11.1 \mathrm{~mm}$ and nominal unsafety factors in structural members up to 4.3 . Around $15 \%$ of columns do not pass stress checks even at the $\mathrm{SDE}$, with unsafety factors reaching 1.6.

The maximum inter-storey drift, assumed as basic damage index for the evaluation of the performance of infills and other drift-sensitive non-structural elements of the building, including the glazed curtain walls, exceed $1 \%$ of the storey height on all storeys during the restitution response phases at the MCE. This corresponds to the development of diffused cracks both in the infills [11] and 
the glass panes $[3,22,23]$, requiring extensive post-quake repair works for the former and the complete replacement of the latter.

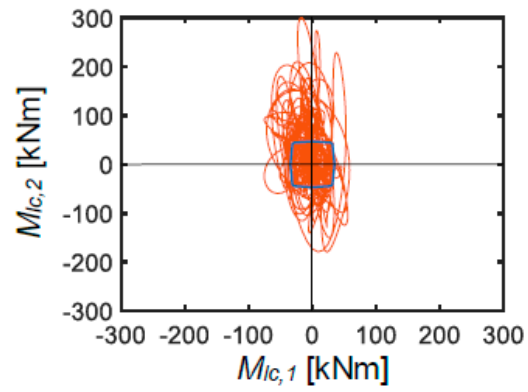

(a)

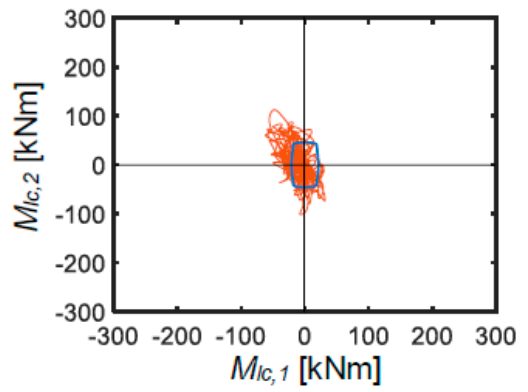

(b)

Figure 12. $M_{l c, 1}-M_{l c, 2}$ biaxial moment interaction curves for a C21-type column on the upper storey (a) and a C20-type column on the first storey; (b) obtained from the most demanding MCE-scaled group of input accelerograms.

The results of the assessment analysis prompt the adoption of a retrofit strategy capable of substantially improving the poor performance evaluated in current conditions and, at the same time, not impairing the architectural value of the building, as discussed in the next section.

\section{Base Isolation Retrofit Hypothesis}

In the wake of the above-mentioned previous studies by the authors concerning the seismic retrofit of irregular structures by means of base isolation [5-9], DCSS devices are adopted for the intervention on the case study building. Indeed, for this type of sliders, the response of the isolation system results to be independent of the characteristics of the superstructure [5,24-29]. As illustrated by the plan in Figure 13 and the two vertical sections highlighted on the underground storeys in Figure 14, the isolators were incorporated at the feet of each column (one isolator per column) and structural wall (two per wall) and below the bottom slabs of the two elevator pits (four per elevator).

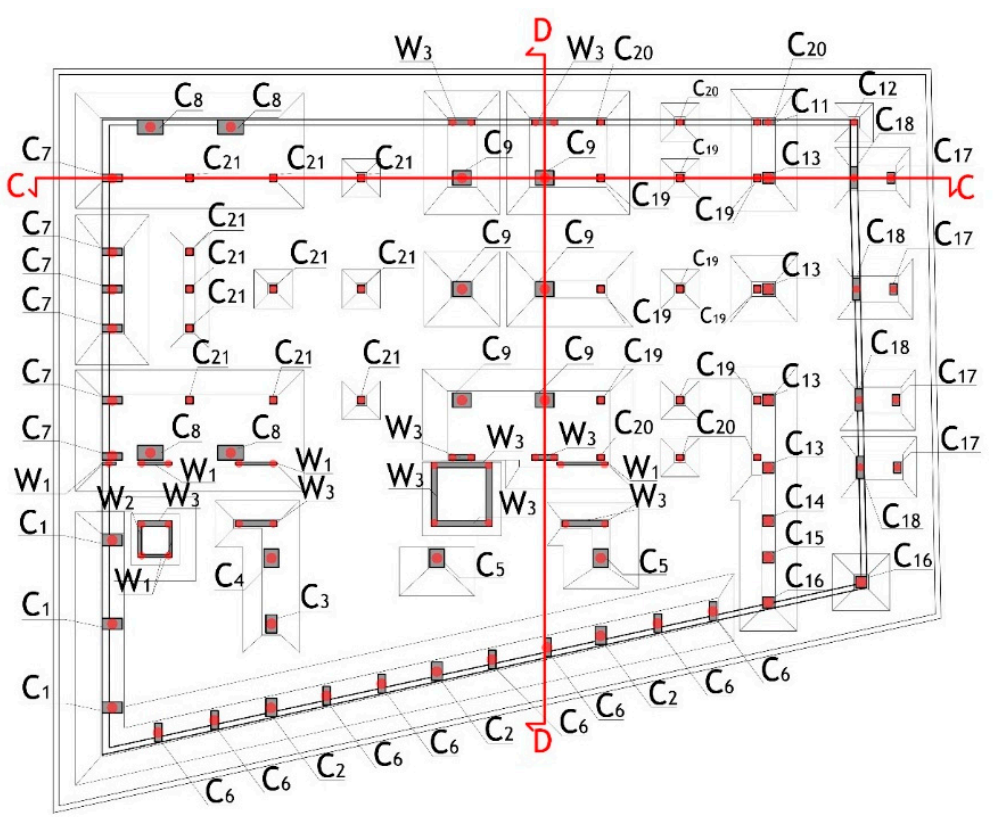

Figure 13. Plan of the foundations of the building with the positions of the DCSS isolators (highlighted with red circles). 


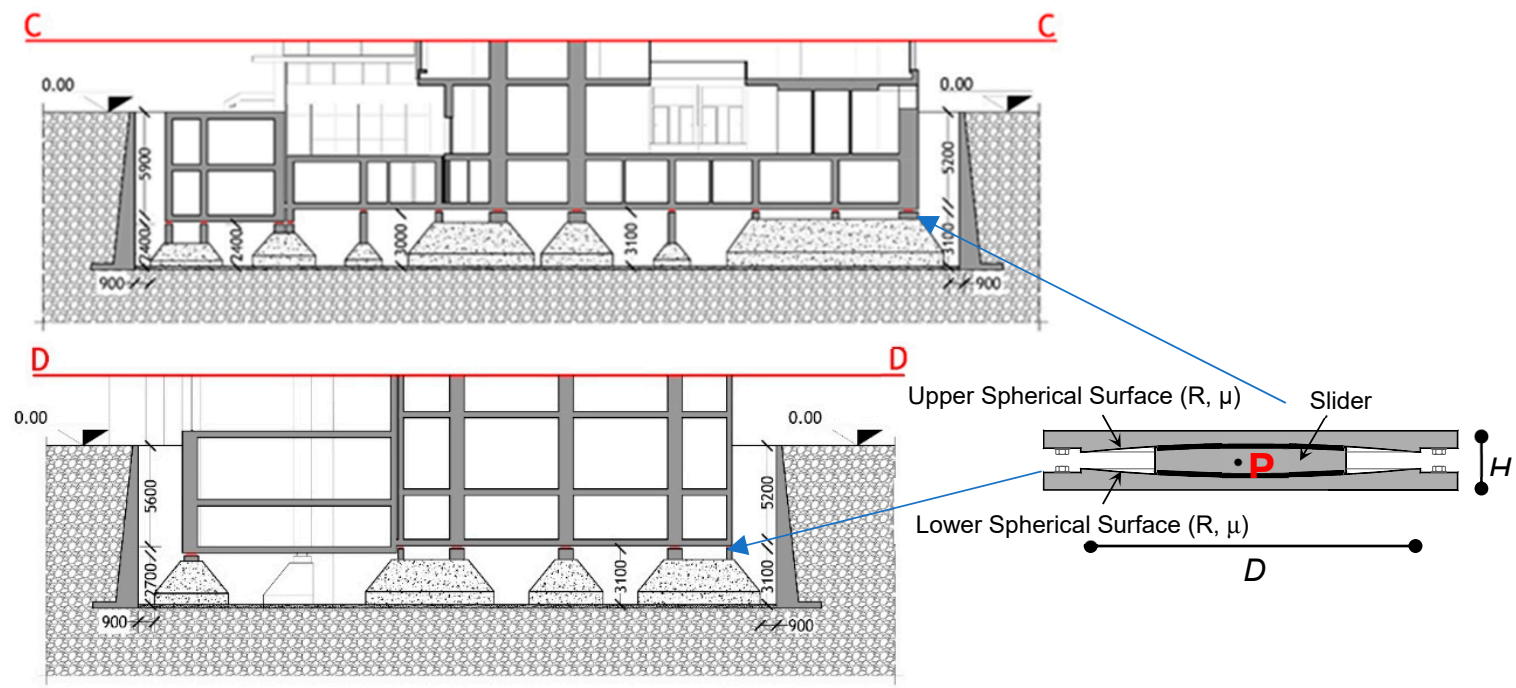

Figure 14. Vertical sections of the building denoted as C-C and D-D in Figure 13.

As is known [5,24], a DCSS isolator consists of two facing spherical concave surfaces, separated by a double convex friction slider (detailed drawing in Figure 14), which produces two independent pendulum response mechanisms. The equivalent vibration period, $T_{e}$, and the equivalent viscous damping coefficient ratio, $\xi_{e}$, of the device are expressed as [5]:

$$
\begin{gathered}
T_{e}=2 \pi \sqrt{\frac{1}{g\left(\frac{1}{L_{D C S S}}+\frac{\mu}{d_{\max }}\right)}} \\
\xi_{e}=\frac{2}{\pi} \frac{1}{\frac{d_{\max }}{\mu L_{D C S S}}+1}
\end{gathered}
$$

where $g=$ acceleration of gravity, $L_{D C S S}=$ effective pendulum length $\left(L_{D C S S}=2(R-h)=2 R-2 h\right.$, with $R=$ radium of pendulum and $h=$ slider center-to-surface distance), $\mu=$ friction coefficient and $d_{\max }=$ maximum displacement of the isolator along all directions in plan.

Based on a preliminary sizing carried out by estimating the maximum vertical force on each isolator and its maximum displacement at the MCE, three types of DCSS devices were selected, named Type-1 through Type-3. The mechanical and geometrical properties of the isolators, as derived from the reference manufacturer's catalogue [30], are as follows: $L_{D C S S}=3100 \mathrm{~mm}, d_{\max }= \pm 200 \mathrm{~mm}$, $\mu=0.025, T_{e}=3.1 \mathrm{~s}, \xi_{e}=15.2 \%$, for all types; $N_{R d}=$ maximum allowable vertical force $=1500 \mathrm{kN}$, $D=$ diameter $=490 \mathrm{~mm}, H=$ height $=114 \mathrm{~mm}$-Type- $; ; N_{R d}=2000 \mathrm{kN}, D=520 \mathrm{~mm}$, $H=109 \mathrm{~mm}$-Type-2; $N_{R d}=2500 \mathrm{kN}, D=540 \mathrm{~mm}, H=106 \mathrm{~mm}$-Type-3.

As visualized in the vertical sections of the underground storeys shown in Figure 14 and the isolator installation drawing in Figure 15, a new floor is built at the base of the second basement level, currently supported by a loose stone layer, to constitute a horizontal rigid diaphragm for the isolation system. This mounting is facilitated by a rather high depth of the water table at the site of the building, evaluated by considering its seasonal fluctuation according to recently proposed criteria [31,32]. The structure of the floor consists of a mesh of primary and secondary HEB 240 and HEA 160 Italian beams made of S235JR grade steel, bearing a $75 \mathrm{~mm}$-high HI-bond corrugated steel sheet, with a 50-mm-thick on-site cast R/C slab on top. 


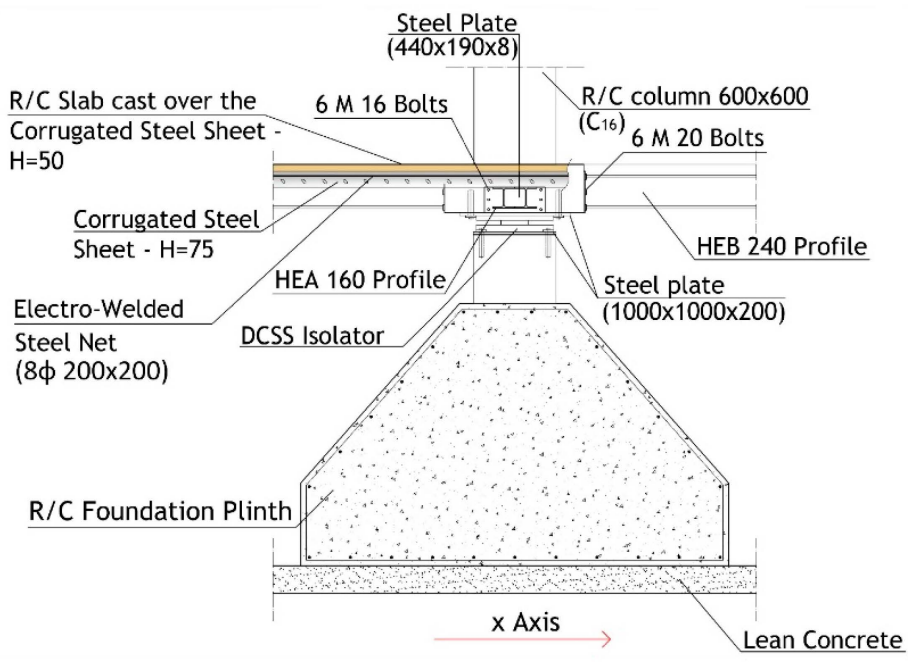

Figure 15. Detail of the installation of a DCSS isolator.

Each isolator is installed by positioning a steel collar around the column, as contrasting element for the electro-hydraulic actuators to which the axial force of the column is transiently transferred; cutting the column portion where the isolator must be placed; inserting the isolator; completing the R/C "capital" that incorporates the collar; finally, fixing the steel beams of the new floor to the capital faces. A general view and a detail of the finite element model of the structure incorporating the isolators are shown in Figure 16.

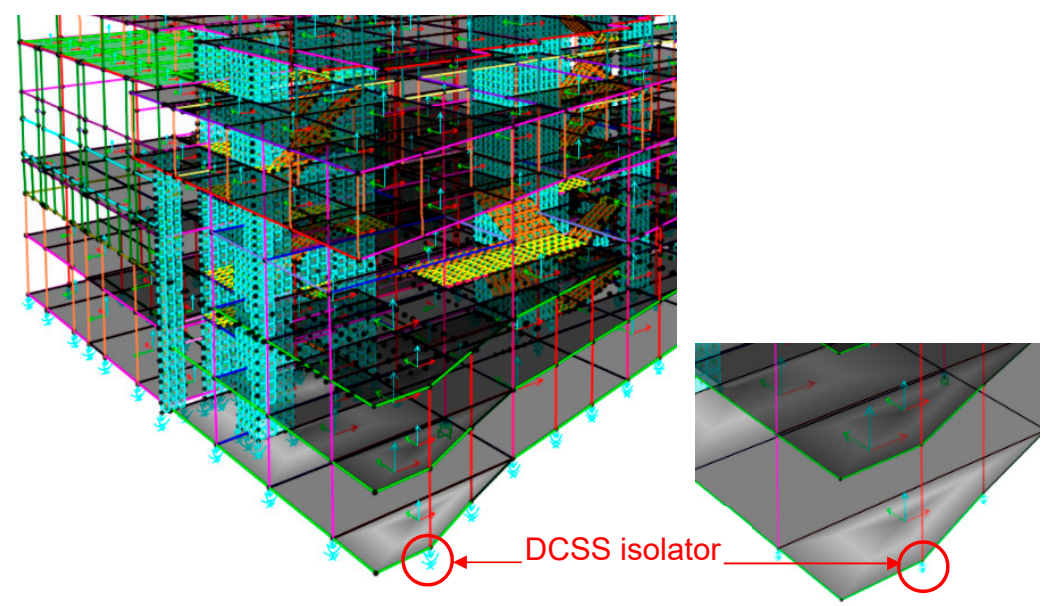

Figure 16. Views of the finite element model of the structure incorporating the base isolation system.

The response of the DCSS devices was simulated by means of the "friction isolator" link element available in the library of SAP2000NL software, i.e., a biaxial pendulum element with sliding friction properties for the displacements along the two reference local axes in plan.

\subsection{Modal Analysis}

The modal analysis of the structure in base-isolated conditions shows a first translational mode both along $\mathrm{X}$ and along $\mathrm{Y}$, with associated modal masses close to $100 \%$ of the total seismic mass, and nearly coinciding vibration periods of Unit 1 and $2(3.15 \mathrm{~s}$, Unit 1 , and $3.17 \mathrm{~s}$, Unit 2-X; $3.18 \mathrm{~s}$, Unit 1, and $3.21 \mathrm{~s}$, Unit $2-\mathrm{Y}$ ). The periods are slightly greater than the $T_{e}=3.1 \mathrm{~s}$ equivalent period of the isolators given by Equation (5) due to the superstructure deformability contribution to these modes. 


\subsection{Time-History and Seismic Performance Verification Analysis}

The results of the final verification analysis are synthesized in Figures 17 and 18, which duplicate, for retrofitted conditions, the graphs in Figures 11 and 12 above.

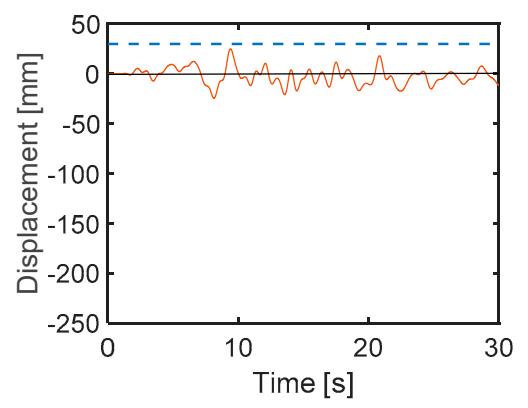

Figure 17. Relative displacement time-history of the pair of contacting joints referred to in Figure 11 obtained from the most demanding MCE-scaled group of input accelerograms.

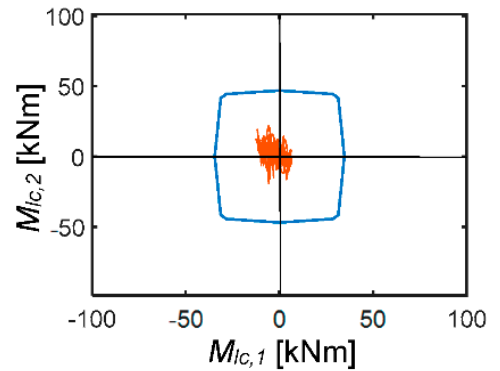

(a)

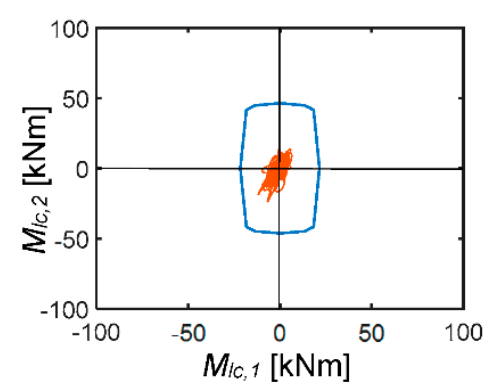

(b)

Figure 18. $M_{l c, 1}-M_{l c, 2}$ interaction curves for the C21-type column (a) and C20-type column (b) referred to in Figure 12 obtained from the most demanding MCE-scaled group of input accelerograms.

The relative displacement time-history obtained for the same pair of contacting joints referred to in Figure 11 is plotted in Figure 17, showing maximum relative displacements of $22.1 \mathrm{~mm}$, which allows the prevention of any pounding impact.

The $M_{l c, 1}-M_{l c, 2}$ biaxial moment interaction curves of the C21-type and C20-type columns referred to in Figure 18 highlight that the response is reduced by a factor greater than 10 for the former, which is the most affected by pounding effects in current state, and nearly equal to $10(\mathrm{C} 20)$, thanks to the mitigating action of the base isolation system. This helps in constraining the response curves within the boundary of the $M_{l c, 1}-M_{l c, 2}$ safe interaction domain with wide margins.

Similar benefits of the retrofit intervention are found for all the other members, which meet the stress state checks up to the MCE level of seismic action too. Furthermore, consistently with the substantial reduction in the lateral displacements of the two units, the maximum inter-storey drifts are shifted below the operational performance level-related limit [2] of $0.33 \%$ of the storey height, preventing damage to infills and other drift-sensitive non-structural elements of the building, including the glazed curtain walls.

By way of example of the response of the isolators, the force-displacement cycles of two DCSS devices situated below a C9-type column and a C19-type column, with sections of $1000 \times 800 \mathrm{~mm}^{2}$ and $400 \times 400 \mathrm{~mm}^{2}$, respectively, are plotted in Figure 19. The greater average width in terms of force of the cycles obtained for the C9-type isolator is a consequence of the notably greater axial force, and thus higher friction forces, acting on it, as compared to the C19-type element. The peak displacements of both isolators, as well as of all remaining ones, are below $140 \mathrm{~mm}$, i.e., considerably smaller than the available device displacements of $\pm 200 \mathrm{~mm}$. 


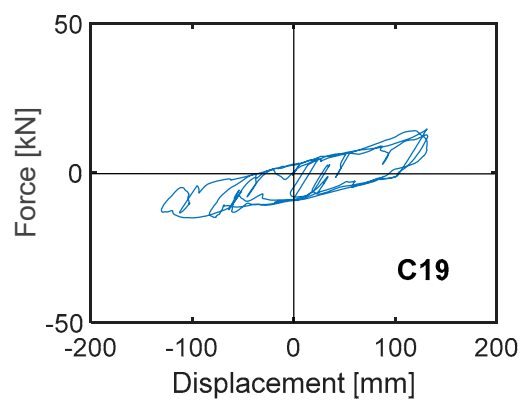

(a)

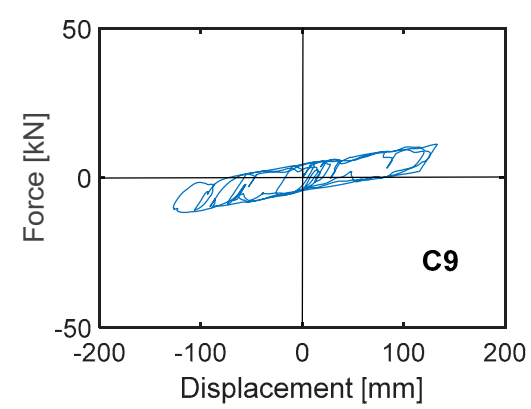

(b)

Figure 19. Response cycles of two isolators placed below a C9-type column (a) and a C19-type column (b) obtained from the most demanding MCE-scaled group of input accelerograms.

The estimated cost of the retrofit intervention is equal to around 130 Euros $/ \mathrm{m}^{2}$, i.e., $50 \%$ lower than the cost of conventional rehabilitation designs, e.g., based on jacketing with steel profiles or fiber-reinforced plastics of the structural members in unsafe conditions. As the base isolation intervention is confined to the second underground level, it does not cause any intrusion on the superstructure, preserving its architecture and preventing significant interruptions of usage of the building.

\section{Conclusions}

Seismic isolation is increasingly adopted in the design of new buildings, with several thousands of applications currently noticed worldwide. At the same time, a considerably smaller number of retrofit interventions based on the use of this protection strategy is observed, with very few examples concerning modern heritage structures.

The study presented here is aimed at providing new contributions to this topic, by extending the field of observation from ordinary buildings and infrastructures, examined at previous steps of this research line, to buildings with $\mathrm{R} / \mathrm{C}$ structure recently included in Italian heritage listings.

Based on the results of the analyses carried out, the following conclusions are drawn.

- The Automobile Club Headquarters in Florence, selected as a representative case study for this stock of buildings, showed seismic performance capacities even poorer than expected for ordinary buildings of the same period. This is due to the peculiar characteristics of its structural system, notably irregular both in plan and elevation, with staggered levels in the lower storeys, some of which suspended to cantilevered beams, poor redundancy of several frame members and a 30-mm-wide only technical gap separating the two main constituting wings.

- Indeed, the results of the time-history performance evaluation analysis highlight that around $15 \%$ of columns do not pass stress checks even at the serviceability design earthquake level, with unsafety factors reaching 1.6.

- At the same time, severe pounding conditions, as assessed by peak interpenetration depth values of $11.1 \mathrm{~mm}$, as well as generally unsafe conditions of structural members quantified by nominal unsafety factors up to 4.3, are found at the basic design earthquake level.

- The interpenetration depth reaches $14.1 \mathrm{~mm}$ at the maximum considered earthquake level, with corresponding total collision forces greater than $13,000 \mathrm{kN}$, which would cause severe damage to the infills in contact with the columns of the colliding alignments and complete disruption of the concrete cover of relevant beams. In addition, the increase in the stress states of the columns belonging to these alignments and the neighboring zones determines nominal unsafety values equal to around 6 .

- The maximum inter-storey drift, assumed as basic damage index for the evaluation of the performance of infills and glazed curtain walls, exceeds $1 \%$ of the storey height at all storeys at 
the MCE. This corresponds to the development of diffused cracks both in the infill panels and the glass panes, requiring extensive post-quake repair works for the former and the complete replacement for the latter.

- $\quad$ The proposed base isolation retrofit intervention guarantees non-pounding response conditions and safe stress states for all members up to the MCE.

- The maximum inter-storey drifts are correspondingly shifted below the operational performance level-related limit of $0.33 \%$ of the storey height. This prevents damage to infills, plants, finishes and the other drift-sensitive non-structural elements, including the imposing glazed curtain walls.

- The absence of intrusion in the building interiors guaranteed by the proposed retrofit solution helps in preserving its fine architectural appearance, in addition to the advantages offered to ordinary buildings (i.e., no significant interruption of usage during the execution of works, no architectural obstruction and reduction of floor areas caused by the incorporation of new structural members and/or by the strengthening of the existing ones, etc.).

- In addition, the estimated cost of the intervention is around $50 \%$ lower than the cost of conventional rehabilitation designs.

Author Contributions: Conceptualization, G.T. and S.S.; methodology, G.T. and S.S.; software, E.F. and I.C.; validation, E.F., I.C., G.T. and S.S.; formal analysis, E.F.; investigation, G.T., E.F. and I.C.; resources, G.T.; data curation, G.T.; writing-original draft preparation, S.S. and G.T.; writing-review and editing, S.S. and G.T.; funding acquisition, G.T. All authors have read and agreed to the published version of the manuscript.

Funding: Financial support from ReLUIS-DPC Project 2019-2021 (Work Package 15: Normative Contributions for Isolation and Dissipation; Project 9-protocol nr. 60-05/02/2019—grant nr. 1100004434, 10.13039/50) is gratefully acknowledged.

Conflicts of Interest: The authors declare no conflict of interest.

\section{References}

1. Iervolino, I.; Manfredi, G.; Polese, M.; Verderame, G.M.; Fabbrocino, G. Seismic risk of R.C. building classes. Eng. Struct. 2007, 29, 813-820. [CrossRef]

2. Jalayer, F.; Elefante, L.; Iervolino, I.; Manfredi, G. Knowledge-Based Performance Assessment of Existing RC Buildings. J. Earthq. Eng. 2011, 15, 362-389. [CrossRef]

3. Sorace, S.; Terenzi, G. Structural assessment of a modern heritage building. Eng. Struct. 2013, 49, 743-755. [CrossRef]

4. Custance-Baker, A.; Mcdonald, S. Conserving Concrete Heritage; The Getty Conservation Institute: Los Angeles, CA, USA, 2014.

5. Sorace, S.; Terenzi, G. A viable base isolation strategy for the advanced seismic retrofit of an R/C building. Contemp. Eng. Sci. 2014, 7, 817-834. [CrossRef]

6. Mori, C.; Sorace, S.; Terenzi, G. Seismic assessment and retrofit of two heritage-listed R/C elevated water storage tanks. Soil Dyn. Earthq. Eng. 2015, 77, 123-136. [CrossRef]

7. Sorace, S.; Terenzi, G.; Bitossi, C.; Mori, E. Mutual seismic assessment and isolation of different art objects. Soil Dyn. Earthq. Eng. 2016, 85, 91-102. [CrossRef]

8. Sorace, S.; Terenzi, G.; Costoli, I. Base isolation strategy for seismic retrofit of water tanks with shaft staging. Int. J. Civ. Eng. Technol. 2018, 9, 891-902.

9. Sorace, S.; Terenzi, G. Analysis, design, and construction of a base-isolated multiple building structure. Adv. Civ. Eng. 2014, 2014, 1-13. [CrossRef]

10. Ministry of Infrastructure and Transport. Update of Technical Standards for Constructions; Ordinary supplement to G.U. no. 42: Rome, Italy, 2018; (In Italian). Available online: https://www.gazzettaufficiale.it/eli/gu/2018/ 02/20/42/so/8/sg/pdf (accessed on 20 September 2020).

11. Ministry of Infrastructure and Transport. Instructions for the Application of the Update of Technical Standards for Constructions; Ordinary supplement to G.U. no. 35: Rome, Italy, 2019; (In Italian). Available online: https://www.gazzettaufficiale.it/eli/id/2019/02/11/19A00855/sg (accessed on 20 September 2020).

12. Toniolo, G.; Di Prisco, M. Reinforced Concrete Design to Eurocode 2; Springer Tracts in Civil Engineering, Springer Nature: Wien, Austria, 2017. 
13. Khosravani, M.R.; Wagner, P.; Fröhlich, D.; Weinberg, K. Dynamic fracture investigations of ultra-high performance concrete by spalling tests. Eng. Struct. 2019, 201, 109844. [CrossRef]

14. SAP2000NL. Theoretical and Users' Manual. Release 21.08; Computers \& Structures Inc.: Berkeley, CA, USA, 2020.

15. Pratesi, F.; Sorace, S.; Terenzi, G. Analysis and mitigation of seismic pounding of a slender R/C bell tower. Eng. Struct. 2014, 71, 23-34. [CrossRef]

16. Licari, M.; Sorace, S.; Terenzi, G. Nonlinear Modeling and Mitigation of Seismic Pounding between R/C Frame Buildings. J. Earthq. Eng. 2015, 19, 431-460. [CrossRef]

17. Jankowski, R. Non-linear viscoelastic modelling of earthquake-induced structural pounding. Earthq. Eng. Struct. Dyn. 2005, 34, 595-611. [CrossRef]

18. Anagnostopoulos, S.A.; Spiliopoulos, K.V. An investigation of earthquake induced pounding between adjacent buildings. Earthq. Eng. Struct. Dyn. 1992, 21, 289-302. [CrossRef]

19. Jankowski, R. Analytical expression between the inpact damping ratio and the coefficient of restitution in the non-linear viscoelastic model of structural pounding. Earthq. Eng. Struct. Dyn. 2006, 35, 517-524. [CrossRef]

20. Goldsmith, W.; Frasier, J.T. Impact: The Theory and Physical Behavior of Colliding Solids. J. Appl. Mech. 1961, 28, 639. [CrossRef]

21. Vanmarcke, E.H.; Fenton, G.A.; Heredia-Zavoni, E. SIMQKE-II-Conditioned Earthquake Ground Motion Simulator: User's Manual, Version 2.1; Princeton University: Princeton, NJ, USA, 1999; Available online: http://nisee.berkeley.edu/documents/SW/SIMQKE-II-V2-1.pdf (accessed on 7 August 2020).

22. ASTM E-1300-04. Standard Practice for Determining Load Resistance of Glass in Buildings; ASTM International: West Conshohocken, PA, USA, 2004.

23. BS 6262-4. Glazing for buildings. Code of Practice for Safety Related to Human Impact; BSI Committee B/520/4: London, UK, 2005.

24. Fenz, D.M.; Constantinou, M.C. Behaviour of the double concave Friction Pendulum bearing. Earthq. Eng. Struct. Dyn. 2006, 35, 1403-1424. [CrossRef]

25. Mazza, F.; Mazza, M. Nonlinear seismic analysis of irregular r.c. framed buildings base-isolated with friction pendulum system under near-fault excitations. Soil Dyn. Earthq. Eng. 2016, 90, 299-312. [CrossRef]

26. Bhagat, S.; Wijeyewickrema, A.C. Seismic response evaluation of base-isolated reinforced concrete buildings under bidirectional excitation. Earthq. Eng. Eng. Vib. 2017, 16, 365-382. [CrossRef]

27. Mazza, F.; Mazza, M. Sensitivity to modelling and design of curved surface sliding bearings in the nonlinear seismic analysis of base-isolated r.c. framed buildings. Soil Dyn. Earthq. Eng. 2017, 100, 144-158. [CrossRef]

28. Habieb, A.B.; Valente, M.; Milani, G. Effectiveness of different base isolation systems for seismic protection: Numerical insights into an existing masonry bell tower. Soil Dyn. Earthq. Eng. 2019, 125. [CrossRef]

29. De Angelis, F.; Cancellara, D. Dynamic analysis and vulnerability reduction of asymmetric structures: Fixed base vs base isolated system. Compos. Struct. 2019, 219, 203-220. [CrossRef]

30. FIP. Anti-Seismic Devices Product Division. 2019. Available online: http://www.fip-group.it (accessed on 4 October 2020).

31. Foroutan, M.; Kassim, A.B.; Amiri, S.T.; Molkararei, P. Coupling effects of suction variation on riverbank stability. Electron. J. Geotech. Eng. 2014, 19, 4427-4438.

32. Luo, Z.; Kong, J.; Ji, Z.; Shen, C.; Lu, C.; Xin, P.; Zhao, Z.; Li, L.; Barry, D. Watertable fluctuation-induced variability in the water retention curve: Sand column experiments. J. Hydrol. 2020, 589, 125125. [CrossRef]

Publisher's Note: MDPI stays neutral with regard to jurisdictional claims in published maps and institutional affiliations.

(C) 2020 by the authors. Licensee MDPI, Basel, Switzerland. This article is an open access article distributed under the terms and conditions of the Creative Commons Attribution (CC BY) license (http://creativecommons.org/licenses/by/4.0/). 